\title{
Estudo das alterações ante-morte da cavidade oral de mãos-peladas (Procyon cancrivorus) de vida livre e de cativeiro ${ }^{1}$
}

\author{
Mônica A.F. Bianchi ${ }^{2 *}$, Luis F.S.P. Mayorga ${ }^{3}$, Ana P.A. Castro ${ }^{3}$ e João L. Rossi Junior ${ }^{3}$ \\ ABSTRACT.- Bianchi M.A.F., Mayorga L.F.S.P., Castro A.P.A. \& Rossi Junior J.L. 2013. [Study \\ of the ante-mortem changes of the oral cavity of crab-eating raccoon (Procyon can- \\ crivorus) free living and in captivity.] Estudo das alterações ante-morte da cavidade oral \\ de mãos-peladas (Procyon cancrivorus) de vida livre e de cativeiro. Pesquisa Veterinária \\ Brasileira 33(5):651-661. UNESC-Centro Universitário do Espírito Santo, Avenida Fioravan- \\ te Rossi 2930, Colatina, ES 29703-900, Brazil. E-mail: monicavets@gmail.com \\ Most diseases of animals in nature and captivity is linked to human proximity, resulting \\ from habitat fragmentation and degradation of these animal habitats, the isolation of the \\ species and the close contact between them and domestic animals and manhood. We stu- \\ died 104 crab-eating raccoons (Procyon cancrivorus) skulls by direct assessment of sheet \\ filling veterinary dental and photographic documentation reporting these abnormalities, \\ which were classified and recorded for statistical purposes. The findings show that the \\ captive animals were most affected with injuries related to periodontal disease, such as \\ calculus, alveolar bone resorption, dehiscence, fenestration, furcation exposure, as well as \\ malocclusion, crowding and severe levels of tooth wear. The free-living animals showed the \\ highest rates of fractures, ante-mortem tooth loss and tooth blackout, which feature larger \\ dental injuries during the feeding process. The intention was therefore to establish a pa- \\ rameter of oral health status of the species studied, their frequency and whether it has the \\ same oral diseases in the wild life and in captivity, relating the prevalence of oral diseases \\ with ecological characteristics of the specie.
}

INDEX TERMS: Wildlife, veterinary dentistry, teeth, sincranium, carnivorous, Procyon cancrivorus, Procyonidae, dental wear, dental trauma.

RESUMO.- A maioria das doenças dos animais de natureza e cativeiro encontra-se associada à proximidade humana, que resulta da fragmentação e degradação do habitat destes animais, no isolamento das espécies e no contato mais próximo entre estes e animais domésticos e o homem. Foram estudados os sincrânios de 104 mãos-peladas (Procyon cancrivorus) por meio de avaliação direta, preenchimento de ficha odontológica veterinária e documentação fotográfica, que relataram anormalidades encontradas, as quais foram classificadas e contabilizadas para fins estatísticos. Os achados deste trabalho aludem que os animais de cativeiro foram mais acometidos com as lesões relacionadas à

\footnotetext{
${ }^{1}$ Recebido em 4 de dezembro de 2012.

Aceito para publicação em 3 de abril de 2013.

${ }^{2}$ UNESC-Centro Universitário do Espírito Santo, Avenida Fioravante Rossi 2930, Colatina, ES 29703-900, Brasil. *Autor para correspondência: monicavets@gmail.com

${ }^{3}$ Universidade Vila Velha (UVV), Rua Comissário José Dantas de Melo 21, Vila Velha, ES 29102-770.
}

doença periodontal, como cálculo, reabsorção óssea alveolar, deiscência, fenestração, exposição de furca, além de maloclusão, apinhamento dentário e os níveis mais graves de desgaste dentário. Os animais de vida livre apresentaram mais altos índices de fraturas, perdas dentárias ante-morte e escurecimento dentário, que caracterizam maior trauma dentário, durante o processo alimentar. Pretendeu-se, assim, estabelecer um parâmetro do estado de saúde oral da espécie estudada, sua frequência e se esta apresenta as mesmas enfermidades orais em vida livre e em cativeiro, relacionando a prevalência de afecções orais com características da ecologia da espécie.

TERMOS DE INDEXAÇÃO: Animais selvagens, odontologia veterinária, dente, sincrânio, carnívoros, Procyon cancrivorus, Procyonidae, desgaste dentário, trauma dentário.

\section{INTRODUÇÃO}

Tipicamente, os procionídeos são animais de pequeno a médio porte, farta pelagem, cauda longa a moderadamente 
longa, com anéis escuros e óbvia máscara facial. São animais adaptados a uma grande variedade de biomas, desde florestas tropicais - onde possuem maior ocorrência - charcos, até regiões semiáridas (Einsenberg \& Redford 1999). Cada ninhada pode ter de quatro a seis filhotes e a fêmea cuida dos filhotes durante um ano (Bellatine et al. 2006). Sua longevidade não está bem estabelecida, mas há relatos de sobrevivência de raccoons (Procyon lotor Linnaeus, 1758), por mais de 20 anos em cativeiro, enquanto que em vida livre, os registros de idade estimada não passam de cinco anos (Phillips \& Olson 2005).

Procyon cancrivorus (Cuvier, 1798) é uma espécie amplamente distribuída em território brasileiro (Einsenberg \& Redford 1999), mas que, entretanto, tem escassa literatura acerca das suas enfermidades orais, especialmente em vida livre (Teixeira \& Ambrosio 2006). Também conhecido como mão-pelada, é um animal solitário, de hábitos noturnos e pouco se sabe a respeito de sua ecologia em vida livre: as limitadas informações se referem ao cativeiro. Arispe et al. (2008), em estudo realizado para a avaliação da densidade populacional, área de ação e atividade do mão-pelada por meio de registros com armadilha fotográfica, reforçaram a tese da difícil avaliação desta espécie, exatamente por seu hábito noturno e crepuscular, e aparente distribuição de baixa abundância e variedade.

A investigação osteológica ante-morte pode revelar inúmeras informações úteis sobre a saúde de um espécime, tais como afecções infecciosas e físicas (Cooper \& Cooper 2008). Os acervos de história natural dos museus são fonte de conhecimento e compreensão sobre as espécies e seus biomas. É possível obter informações sobre o tipo de alimentação desses animais, durante a vida, o grau de poluição química que os circundava enquanto forrageavam plantas, por exemplo; e possivelmente outras informações que ainda não sabemos revelar (Elbroch 2006). Tal fato se torna viável porque os dentes compõem o tecido mais duro do organismo, tornando-se por vezes o único vestígio da existência de espécies já extintas (Kowaleski 2005).

Enfermidades orais têm sido relacionadas com afecções que envolvem debilitação geral do paciente, visto que a cavidade oral dá início ao processamento de qualquer alimento ingerido pelo organismo e, desta maneira, a manutenção da higidez das estruturas orais, tais quais dentes, periodonto e língua é essencial para a sanidade do organismo em geral (Pachaly \& Gioso 2001). Médicos Veterinários de animais selvagens deveriam adotar e seguir um estrito protocolo para exame da cavidade oral de um animal, sempre que anestesiado (Fecchio et al. 2008, Gioso et al. 2008). Apesar de algumas afecções serem mais prevalentes, é importante que o exame da cavidade oral avalie tanto os tecidos duros: dente e osso (presença de cálculo, cárie, fratura, mobilidade e desmineralizações) como os tecidos moles: lábio, língua, gengiva, palato, bochechas e faringe (inchaços, sangramentos, ulcerações e coloração) (Fecchio et al. 2009). Quanto à possibilidade de verificação do período em que se instalou determinada lesão em crânios avaliados, Elbroch (2006) afirmou que frequentemente faltam dentes em crânios de animais mais velhos e que este achado pode ser diferenciado de perdas ocorridas ante-morte. Se forem observados dentes quebrados, mas arredondados na borda da fratura, o achado indica sinal de desgaste e que esta perda ocorreu quando o carnívoro era vivo, e tinha idade mais avançada.

Rossi Junior (2007) constatou que algumas alterações congênitas ou adquiridas de conformação craniana só foram possíveis de ser constatadas em peças anatômicas. Os dentes perdidos em vida (ante-morte) possuíam a borda do osso alveolar correspondente remodelado ou completamente absorvido, enquanto que nos dentes perdidos pós-morte não havia nenhum remodelamento do osso alveolar. Perfurações causadas por projéteis de arma de fogo e os ossos alveolares de elementos dentários perdidos são reparados inicialmente por um tecido ósseo esponjoso mais macio, que preenche a área comprometida. Se o animal sobreviver, após um trauma, dentes quebrados sofrerão desgastes das bordas das fraturas e terão um aspecto mais alisado, podendo ter alteração de cor com tempo. Doenças e traumas deixam sinais visíveis nos crânios e nos demais ossos dos animais. Alterações na superfície óssea do crânio ou no osso alveolar e nas raízes dos dentes que sofreram remodelação podem revelar enfermidades que o animal sofreu quando vivo (Elbroch 2006). Rossi Junior (2007) referiu que, com relação aos trabalhos com sincrânios, as análises neste tipo de material foram extremamente valiosas, pois revelaram condições adversas que os animais enfrentaram em ambiente natural, que provavelmente não tenham sido determinantes de suas mortes. Os processos reparadores encontrados nos ossos do crânio e dentes foram indicativos de que os animais passaram por enfermidades e que conseguiram sobreviver a elas.

Ao se comparar a dentição de $P$. cancrivorus com qualquer membro de outra família de carnívoros, como a dos felídeos, por exemplo, nota-se marcada diferença na anatomia dentária, revelando suas distintas habilidades mastigatórias, a começar pela grande variação no número de dentes (procionídeos $\mathrm{N}=40$, felídeos $\mathrm{N}=30$ ), embora haja exceções nessas duas famílias (Zeveloff 2002 Teixeira \& Ambrosio 2006, Rossi Junior 2007). Por um lado, a mordida de um gato doméstico, onça-pintada ou pequeno felídeo selvagem apresenta um arranjo em forma de tesoura, da oclusão dos dentes carniceiros, o que é realçado pelo fato de a articulação da mandíbula ser mais baixa, permitindo que a interseção entre os dentes terceiro e quarto pré-molares superiores e os dentes quarto pré-molar inferior e molar inferior forme tal arranjo, altamente especializado na secção de músculos e vísceras - tecidos moles (Rossi Junior, 2007). Por sua vez, a dentição dos procionídeos é adaptada para dieta onívora, pela transformação dos dentes carniceiros, que tipicamente possuem cúspides altas e finas (Evans, 2002) e que em toda a família Procionidae é composto por quatro cúspides e mais arredondado que o dos outros carnívoros (Zeveloff 2002). Os quartos pré-molares maxilares e os primeiros molares mandibulares são comumente chamados de carniceiros (Verstraete 2007). Os dentes molares do mão-pelada possuem quatro cúspides, são largos, e bem adaptados ao esmagamento dos alimentos. Sua fórmula dentária é: I 3/3, C 1/1, PM 4/4, M 2/2 = 40 dentes (Zeveloff 2002, Teixeira \& Ambrosio 2006). Seus 
quartos pré-molares são mais maciços, mais largos e têm as cúspides mais arredondadas que os dos raccoons, encontrados na América do Norte. Seus dentes são mais adaptados para mastigação de itens duros, como crustáceos e conchas de moluscos (Zeveloff 2002). A etiologia da maioria das doenças orais está relacionada com características físicas de sua dieta e às mudanças químicas a que estas dietas induzem (Fitch \& Fagan 1982).

0 presente trabalho visa identificar e relatar o padrão de dentição fisiológica, a ocorrência de alterações da cavidade oral e a sua prevalência, detectadas por meio do estudo de sincrânios de Procyon cancrivorus.

\section{MATERIAL E MÉTODOS}

Foram estudados 104 sincrânios de mãos-peladas; 20 deles procedentes dos acervos do Museu Paraense Emílio Goeldi (MPEG), 41 provenientes do Museu Nacional do Rio de Janeiro/Universidade Federal do Rio de Janeiro (MN), 37 provenientes do Museu de Mastozoologia da Universidade de São Paulo (MZUSP), e seis na Universidade Vila Velha, no Espírito Santo (UVV-ES). 0 trabalho foi realizado nas bancadas dos museus mencionados, sobre base milimetrada. Os exames físicos dos sincrânios foram feitos macroscopicamente utilizando-se documentação fotográfica, e os resultados obtidos foram catalogados individualmente em fichas odontológicas específicas para a espécie. As fichas odontológicas, denominadas odontogramas, foram confeccionadas com base no modelo do Laboratório de Odontologia Comparada (LOC) vinculado ao Departamento de Cirurgia (VCI) da FMVZ-USP, adaptadas especialmente para serem utilizados em sincrânios da espécie estudada. Por meio de documentação fotográfica, foram registradas as anormalidades encontradas, as quais foram classificadas e contabilizadas para fins estatísticos. Pretendeu-se, assim, estabelecer um parâmetro do estado de saúde oral da espécie estudada, e se esta apresenta as mesmas enfermidades orais em vida livre e em cativeiro, relacionando a prevalência de afecções orais com características da ecologia da espécie. $\mathrm{Na}$ avaliação da cavidade oral, foram considerados os seguintes parâmetros de estado de saúde oral: ausência dentária; exposição de dentina ou cemento; desgaste dentário; posicionamento dos dentes, que podem ser causa de maloclusão, hábitos oclusais parafuncionais e perda de suporte ósseo, entre outras; traumatismo e doença periodontal, evidenciada por reabsorção de crista alveolar, cálculo dentário e exposição de furca, segundo recomendado por Rossi Jr (2002).

A classificação de doença periodontal nos sincrânios restringiu-se à avaliação do osso alveolar, devido à ausência dos tecidos moles que compõem o periodonto. Logo, a doença periodontal grau um (gengivite) não pode ser avaliada neste grupo, assim como a mobilidade, por não haver os tecidos moles inerentes.

Os sincrânios foram avaliados quanto à presença de assimetria e lesões ósseas e de oclusão. Os dentes e osso alveolar foram inspecionados visualmente.

A reabsorção óssea foi estimada em milímetros, por sonda milimetrada, tomando-se a medida da distância entre a junção amelo-cementária (JAC) e a crista alveolar, nas faces ósseas mesial, vestibular, distal e palatina ou lingual. Foi estabelecida a subtração padrão de 1,5 mm a partir da JAC, a fim de caracterizar a medida do espaço biológico, ocupado pelo epitélio juncional e inserção conjuntiva.

Para determinação de fenestração e deiscência ósseas, foi adotada metodologia descrita por Davies et al. (1974), isto é, considerou-se deiscência o defeito ósseo vertical apresentando medida de crista óssea igual ou superior a $4 \mathrm{~mm}$, comparada à crista alveolar adjacente, com base na JAC; e fenestração a descontinuidade óssea circunscrita, localizada no osso maxilar causando exposição radicular, sem comprometimento da margem da crista alveolar. A ausência dentária foi distinguida entre ante e pós-morte de acordo com a forma e o padrão da margem óssea alveolar. Considerou-se a perda dentária ante-morte, quando observadas, na região do osso alveolar correspondente, as seguintes características: contorno irregular ou arredondado da crista óssea alveolar, diminuição da profundidade do alvéolo, reação periosteal exuberante e aumento da vascularização, evidenciada pela presença de grande número de foraminas (Verstraete et al., 1996b).

Essas aferições foram tomadas com sonda milimetrada de uso odontológico. 0 trabalho foi realizado nas bancadas dos museus mencionados, sobre base milimetrada. Os exames físicos dos sincrânios foram feitos macroscopicamente utilizando-se documentação fotográfica, e os resultados obtidos foram catalogados individualmente em fichas odontológicas específicas para a espécie.

Toda informação armazenada a respeito do animal, que estava contida no material estudado foi recolhida, mas nem todos possuíam registro completo, ficando alguns dados não determinados. Entretanto, os dados colhidos foram contabilizados e analisados para avaliação de significância estatística. Os dados foram classificados por sexo, biomas, região brasileira onde foram coletados os indivíduos e causa da morte. Para avaliação dos resultados, foi realizada análise descritiva e comparativa dos dados obtidos entre indivíduos de vida livre e de cativeiro. As informações foram compiladas em planilha criada em programa de computação especialmente desenvolvido para este estudo, em linguagem Delphi, e os valores armazenados e gerenciados em banco de dados Microsoft Office Access $2007^{\circledR} \mathrm{i}$, que foi denominado Odontograma de Procionídeos. Não foi possível efetuar exame radiográfico para caracterizar o tipo de ausência dos elementos dentários, nem anomalias de raízes, por não haver, nas coleções de referencia visitadas, disponibilidade de aparelhos radiográficos, nem os pesquisadores disporem deste equipamento portátil.

\section{RESULTADOS}

Dentre os 104 exemplares de Procyon cancrivorus avaliados, todos os sincrânios com dentição permanente apresentaram fórmula dental I $3 / 3, \mathrm{C} 1 / 1, \mathrm{P} 4 / 4, \mathrm{M} 2 / 2=40$, caracterizados pela presença do elemento dentário ou pelo espaço alveolar correspondente, nos casos de perda dentária. A distribuição de variação sexual está representada na Figura 1. Em relação ao ambiente, $11 \%$ dos espécimes eram prove-

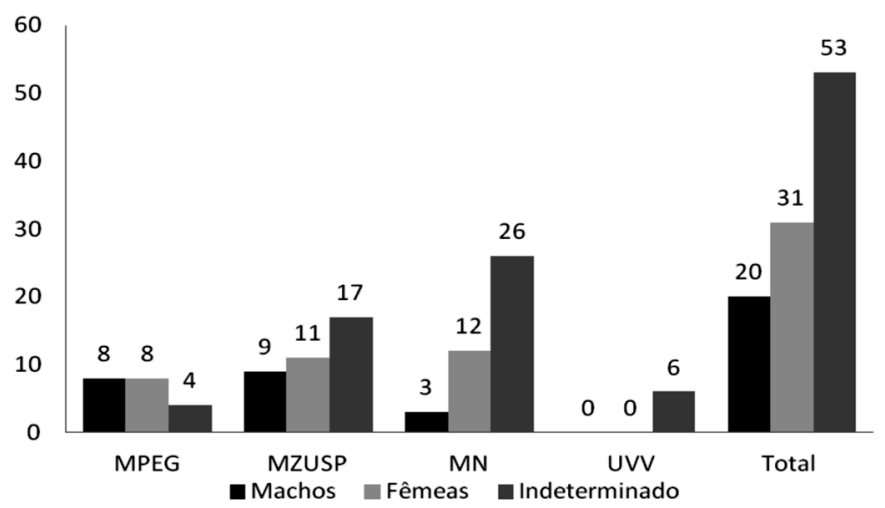

Fig.1. Mão-pelada (Procyon cancrivorus), sincrânios: Distribuição de variação sexual por cada acervo, separadamente. 0 alto número de peças com informações indeterminadas foi presente em quase todas as coleções, exceto do Museu Paraense Emilio Goeldi. O número total de identificação de variação sexual foi igual ao número de não determinados. 
nientes de vida livre, 33\% provenientes de cativeiro e $56 \%$ de origem indeterminada. Foram analisados exemplares coletados nas regiões Norte (7\%), Nordeste (4\%), Sudeste (31\%), Sul (6\%) e Centro-Oeste (8\%). Um espécime era proveniente da cidade de Buenos Aires, Argentina ( $n=2562$ MZUSP), que para fins estatísticos foi incluído no grupo da região Sul. A causa da morte foi referida em raros registros, sendo 11 por atropelamento, 1 por afogamento e 90 por causas não determinadas. Ao todo 15 sincrânios foram excluídos das estatísticas, por apresentarem dentição mista. O número de indivíduos provenientes do acervo da UVV-ES foi reduzido, por se tratar exclusivamente de animais procedentes de atropelamento por veículos automotores. Nestes casos, as lesões geradas por impactos repetidas vezes atingiram de forma devastadora os ossos, inclusive os da cabeça.

As principais alterações orais observadas nos $P$. cancrivorus foram anomalia dentária (AD), erosão de esmalte (EE), doença periodontal (DP), fratura dentária (FD), fatura de esmalte (FE) e pigmentação de esmalte (PE), dentre outras alterações (0) (Fig.2).

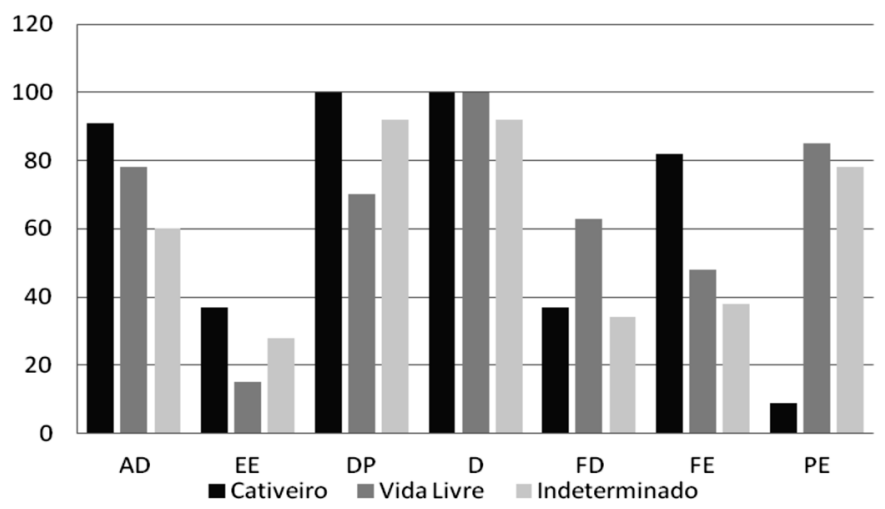

Fig.2. Mão-pelada (Procyon cancrivorus), sincrânios: Prevalência de afecções orais relacionadas com o ambiente, onde anomalia dentária $(\mathrm{AD})$, erosão de esmalte (EE), doença periodontal (DP), fratura dentária (FD), fatura de esmalte (FE) e pigmentação de esmalte (PE), dentre outras alterações $(0)$.

\section{Anomalias dentárias}

As anomalias dentárias foram observadas em 61 espécimes, correspondendo a $68,54 \%$ do total de 89 animais. Tais alterações foram classificadas quanto a: anatomia dentária, posicionamento e número de dentes. Giroversão e apinhamento dentário tiveram maiores percentuais neste estudo. Outros achados de anomalias dentárias foram notados, tais quais: ausência dentária, persistência de decíduo, maloclusão e diastema. Com relação à anomalia dentária de número, foi observada ausência de dentes, mas não a presença de dentes supranumerários. A ausência dentária foi observada em três espécimes, acometendo o elemento dentário 202 ou 203 de um, 105 e 205 em outro e o 105 no terceiro. As ausências ante-morte incluíram agenesia congênita ou dentes inclusos, em que a falta do elemento dentário esteve relacionada com a total ausência do espaço mandibular correspondente, onde se inseriria normalmente aquele dente. Foram totalizados 64 indivíduos com perdas dentárias. As perdas ante-morte ocorreram em $42,7 \%$ dos indivíduos, e as consideradas pós-morte em $58,42 \%$. Ao exame visual, evidenciam-se as diferenças quanto à morfologia óssea alveolar, observadas nas ausências dentárias ante e pós-morte (Fig.3). Os achados aqui relatados foram ocasionais, em dentes que se soltaram após a morte e foram preservados, não tendo, portanto, relevância estatística, servindo apenas como relato da presença de tais alterações na espécie estudada. Três espécimes, todos de procedência não determinada, apresentaram dentes maxilares com raízes fusionadas. Não foi observada esta afecção em dentes mandibulares. A presença de raiz acessória foi observada em dois sincrânios.

Dentre as anomalias de posicionamento dos dentes, $51,68 \%$ dos indivíduos estavam acometidos com giroversão dentária, afetando especialmente os pré-molares mandibulares, sendo que, dentre esses os segundos pré-molares, bilateralmente, foram os mais atingidos $(49,43 \%)$, seguidos pelos terceiros pré-molares $(16,85 \%)$, sendo que a giroversão combinada entre dois ou mais dentes mais prevalente foi a que afetava ambos os dentes, bilateralmente $(14,6 \%)$. Não foi encontrada diferença estatisticamente significativa desta alteração entre os indivíduos provenientes de cativeiro $(66,66 \%)$ e os de vida livre $(62,96 \%)$. Vinte e sete sincrânios apresentaram apinhamento dentário, equivalente a $30,34 \%$ do total avaliado, sendo $10 \mathrm{em}$ animais de cativeiro (83,33\% dos animais de cativeiro), seis de vida livre $(22,22 \%$ dos animais de vida livre) e 11 de procedência desconhecida ( $22 \%$ dos animais de origem indeterminada). Houve diferença significativa entre os animais de vida livre e de cativeiro. Os dentes incisivos inferiores e primeiro pré-molar superior foram os mais acometidos.

\section{Maloclusão}

A investigação de maloclusão foi prejudicada no presente estudo, pelo pobre estado de conservação de grande parte dos sincrânios, ou por fraturas cranianas e de mandíbula ante-morte, que impediram a perfeita coaptação entre maxila e mandíbula, com congruência da articulação têmporo-mandibular. Mas nas 45 amostras que estavam viáveis, foram encontrados 10 casos de maloclusão (11,23\% do total de espécimes estudados), sendo cinco em animais de cativeiro ( $41,67 \%$ dos animais de cativeiro estudados) e cinco de procedência não determinada $(10 \%$ dos animais de origem não determinada), não sendo encontrada em animais conhecidamente de natureza.

\section{Erosão de esmalte}

Erosão de esmalte foi encontrada em $24,72 \%$ dos espécimes, sendo mais prevalente nos dentes incisivos e caninos. Não houve diferença estatística entre os animais oriundos de cativeiro e os de vida livre. Foi encontrada uma lesão sugestiva de cárie em dente 309 de um espécime originário de cativeiro, que não pôde ser confirmada microscopicamente, pois para isso seria necessária a extração do dente para exame histopatológico, acarretando em danos à peça de coleção.

\section{Doença periodontal}

Nos sincrânios estudados, diversas alterações evidentes na morfologia do osso alveolar puderam ser obser- 

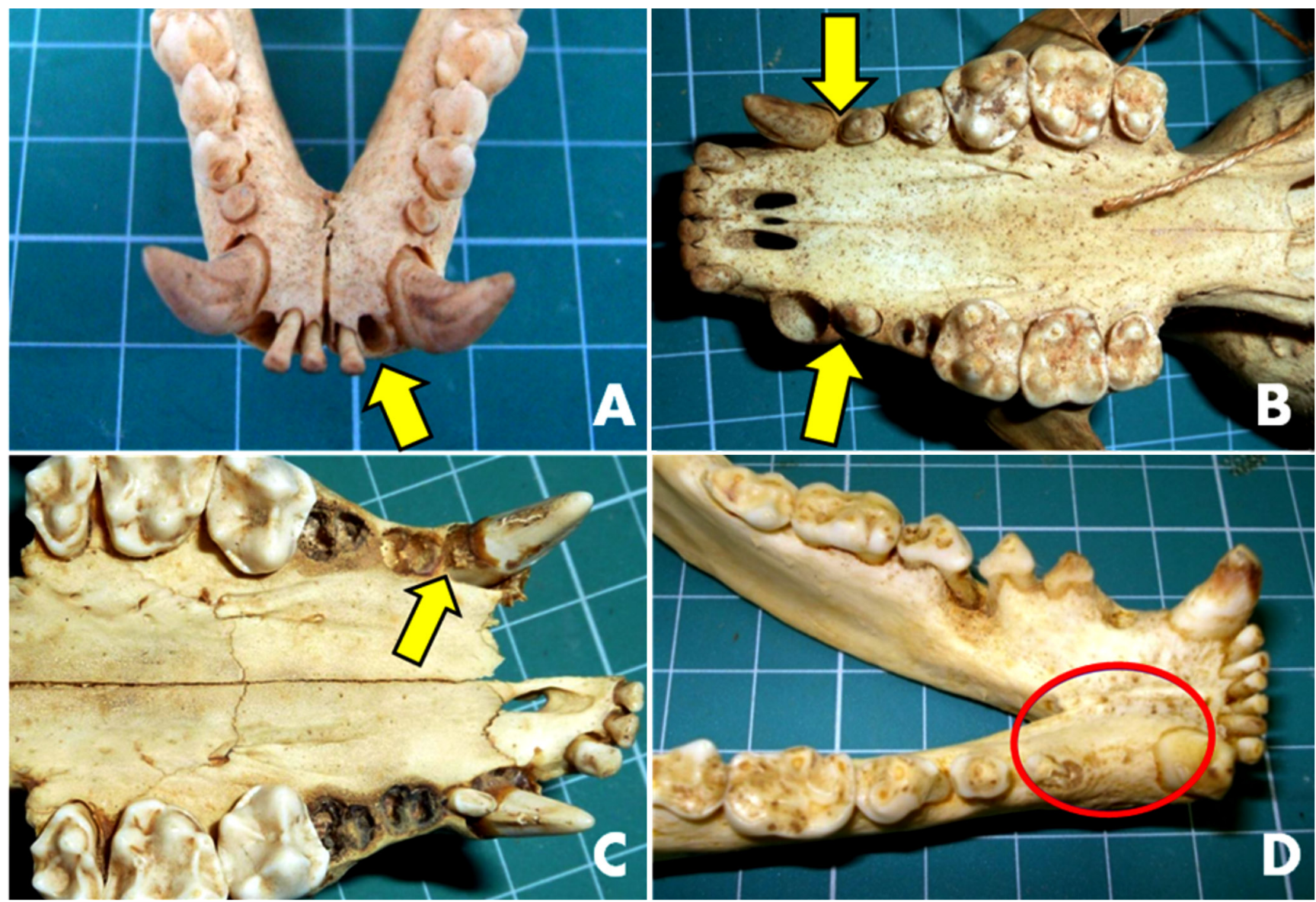

Fig.3. Mão-pelada (Procyon cancrivorus), sincrânios: (A) Espaço alveolar, resultado da perda pós-morte de um incisivo, onde deveria haver mais um. Observar a ausência de remodelação. (B) Ausência 105 e 205, sem espaço vestigial correspondente, que se espera que esteja presente em caso de perda dentária. (C) Ausência de espaço alveolar referente ao elemento dentário 105. (D) Perda dentária ante morte de 306 e 406. Notar a remodelação óssea alveolar ocorrida na região onde faltam os dentes. Processo evidenciado no hemi-arco direito.

vadas, indicativas de doença periodontal. Foram encontrados 76 indivíduos com doença periodontal, $85,39 \%$ do total de sincrânios estudados. Desses, 11 (12,36\% do total) eram de cativeiro e 19 ( $21,35 \%$ do total) de natureza. Relativamente, essas alterações representaram $91,67 \%$ e $70,37 \%$ do total dos animais de cativeiro e de vida livre estudados, respectivamente. A distribuição das lesões indicadoras de doença periodontal está representada na Figura 4. Foi registrada a presença de cálculo nos diversos graus, tendo sido graduada com base no escore proposto por Lascala e Moussalli (1980), onde o grau 0 representa a ausência de cálculo dentário; grau 1, cálculo supragengival recobrindo até um terço da superfície exposta do dente; grau 2 equivalendo a cálculo supragengival recobrindo o espaço equivalente a um terço e não mais que dois terços da superfície do dente, ou presença de pequenos depósitos de cálculo subgengival ao redor da porção cervical do dente; e grau 3, o cálculo supragengival, recobrindo mais de dois terços da superfície do dente, ou presença de banda contínua de cálculo subgengival ao redor da porção cervical do dente. Essa alteração acometeu 52 sincrânios, equivalente a $58,43 \%$ do total, sendo que 10 em 12 animais de cativeiro apresentaram esta afecção (83,33\%), e 14 em 27 espécimes procedentes de natureza
(51,85\%). Quanto à graduação das lesões, apresentaram grau acima de dois 10 amostras derivadas de cativeiro (83,33\% do total de animais de cativeiro), 11 (40,74\%) de vida livre e 24 (48\%) de origem não determinada, perfazendo um total 45 espécimes. Foi encontrada diferença estatisticamente significativa na amostra estudada.

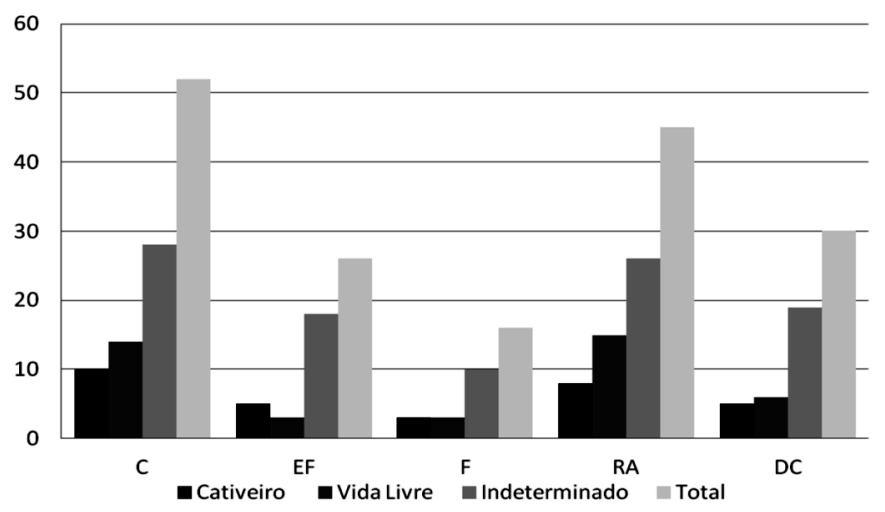

Fig.4. Mão-pelada (Procyon cancrivorus), sincrânios: Representação gráfica da distribuição das doenças relacionadas com doença periodontal, por ambiente e no total: cálculo (C), exposição de furca (EF), fenestração (F), reabsorção alveolar (RA) e deiscência (DC). 
A Figura 5 apresenta a incidência da lesão nos diversos elementos dentários. Os dentes mais afetados foram os quartos pré-molares $(42,30 \%)$, os primeiros molares inferiores $(40,38 \%)$ e os terceiros pré-molares superiores $(34,61 \%)$, em todos os ambientes estudados. Diferença estatisticamente significativa foi encontrada na presença de cálculo em espécimes de vida livre $(40,74 \%)$ e de cativeiro (83,33\%). Exposição de furca foi encontrada em 26 sincrânios $(29,21 \%)$, sendo mais prevalente nos segundos e terceiros pré-molares mandibulares.

Os defeitos ósseos de fenestração óssea alveolar e de reabsorção óssea alveolar foram encontrados, respectivamente, em 17,98\% e 50,56\% dos 89 sincrânios avaliados. Dentre os espécimes que apresentaram reabsorção óssea alveolar, 33,70\% apresentaram deiscência, pois as lesões ultrapassaram a $4 \mathrm{~mm}$; cinco eram provenientes de cativeiro (41,67\% dentre todos os animais de cativeiro); seis de vida livre $(22,22 \%$ do total de vida livre) e 19 de origem não determinada (38\%). A prevalência de deiscência se deu nos segundos molares superiores, em sua maioria, mas também foi observada em outros dentes, como nos primeiros molares maxilares. Nos casos de fenestração óssea, três eram animais de cativeiro $(27,27 \%)$, três de vida livre $(11,11 \%)$ e 10 de origem desconhecida (20\%). Observou-se diferença estatística significativa entre animais de cativeiro e de vida livre quanto a estes defeitos ósseos. Fenestração bilateral foi um achado eventual (26,7\%), na face vestibular da região molar de sincrânios apresentando dentição mista, que não entraram nas estatísticas acima, sendo que dentre esses não houve determinação da procedência. Não houve casos de deiscência e fenestração observados em mandíbula, se limitando à maxila.

\section{Desgaste dentário}

O desgaste dentário, resultado do atrito fisiológico, durante a mastigação e exacerbado nas situações em que os dentes sofrem injúrias ou maloclusão, brigas ou contato frequente com objetos duros e grades de recintos (Forrier et al., 1969; Wiggs \& Lobprise, 1997), esteve presente em 85 exemplares, totalizando 95,51\% dos sincrânios estudados, sendo $100 \%$ dos procedentes de vida livre e de cativeiro e $8 \%$ dos de procedência indeterminada, nos diversos níveis avaliados, com base no escore relatado por Rossi Jr., 2007, onde nível 0: sem desgaste; nível 1: desgaste somente de esmalte; nível 2: formação de dentina terciária; nível 3: exposição da câmara coronária; nível 4: desgaste total da coroa até o nível radicular, com separação completa das raízes nos dentes multirradiculados.

Dentre estes, os sincrânios de animais procedentes de cativeiro possuíam em média $13,48 \%$ dos seus dentes afetados, enquanto que os de vida livre apresentaram $30,33 \%$ dos dentes com algum grau de desgaste. Não foi observada diferença significante entre os indivíduos procedentes de cativeiro ou de natureza $(100 \%$ acometidos, os dois grupos). No entanto, ao se comparar a incidência dos níveis mais graves, encontrou-se $75 \%$ de animais de cativeiro e $55,55 \%$ de vida livre, acometidos com pelo menos um dente com desgaste dental grau 3 ou 4 (Fig.6). Foi observada correlação entre o nível de desgaste e problemas de malo-

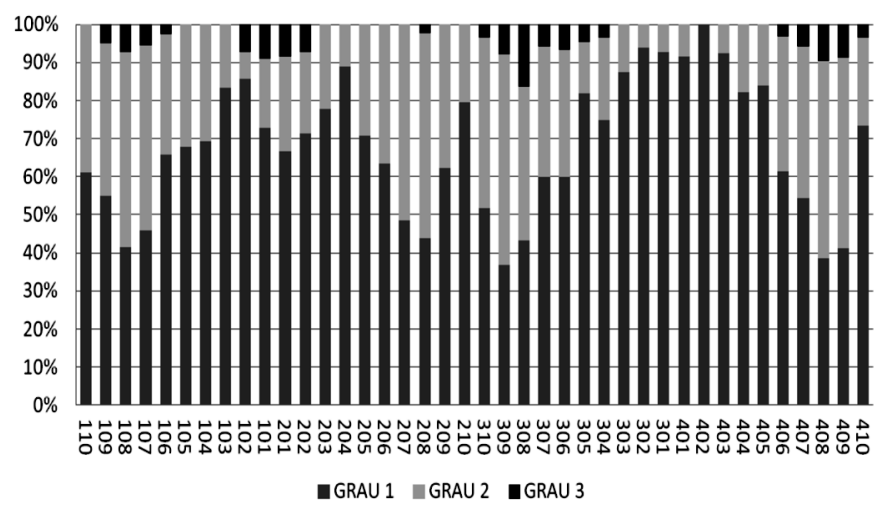

Fig.5. Mão-pelada (Procyon cancrivorus), sincrânios: Distribuição média dos diversos graus de cálculo (variando de 1 a 3, conforme gravidade), classificados por dentes (identificados pelo método Triadam modificado) dos animais avaliados no estudo.

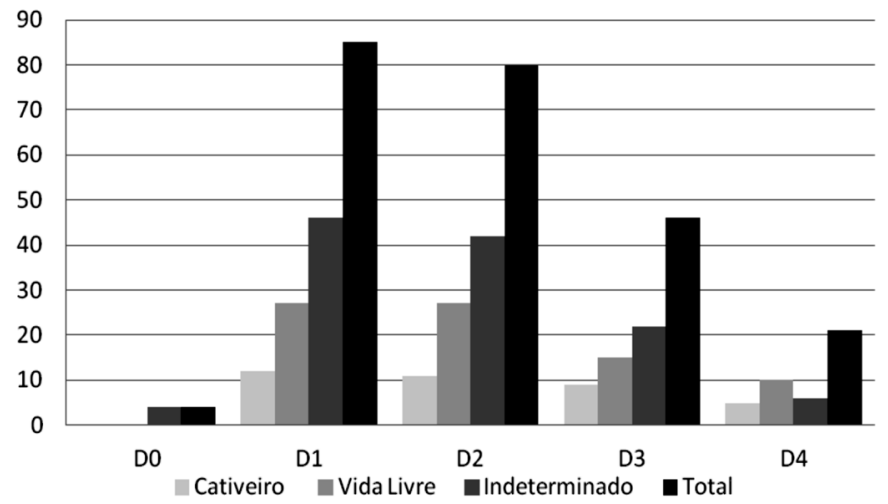

Fig.6. Mão-pelada (Procyon cancrivorus), sincrânios: Relação entre níveis de desgaste dentário e ambiente. D0: sem desgaste, D1: desgaste somente de esmalte, D2: formação de dentina terciária, D3: exposição da câmara coronária e D4: desgaste total da coroa até o nível radicular, com separação completa das raízes nos dentes multirradiculados.

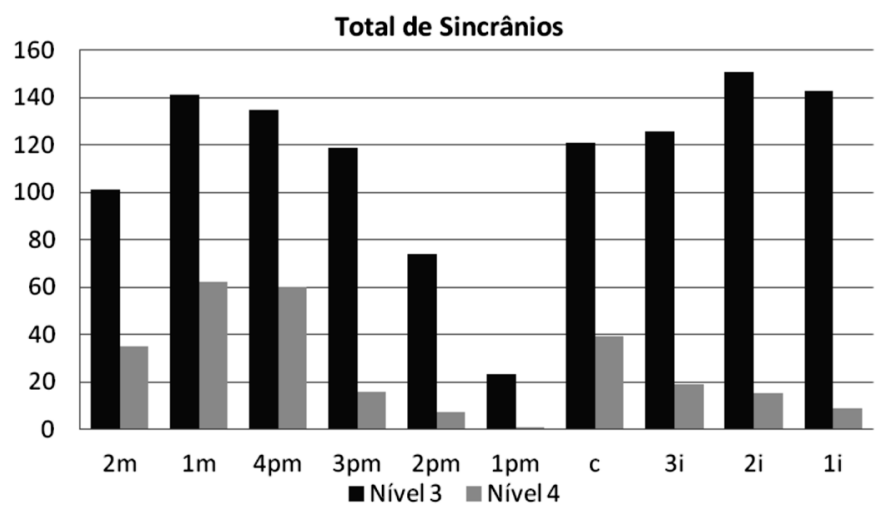

Fig.7. Mão-pelada (Procyon cancrivorus), sincrânios: Prevalência do acometimento de desgaste dentário níveis 3 e 4 por tipo dentário.

clusão em animais pertencentes ao acervo do MPEG, coletados entre o período de 1908 e 1944, todos pertencentes a Jardim Zoológico. Os dentes mais afetados foram os incisivos e os molares (Fig.7). Os dentes mais acometidos com desgaste nível 4, foram os 1M e os 4PM. Desgaste dentário foi assiduamente acompanhado de formação de dentina 
terciária, conforme aumentava sua graduação, ocorrendo em $89,88 \%$ dos animais com desgaste, inclusive em dentes decíduos como em 19379 MZUSP. Em 11 casos foi encontrada exposição de câmara pulpar, onde havia desgaste nível quatro, sendo que três sincrânios eram provenientes de cativeiro, cinco de vida livre e três de procedência não determinada. A face oclusal dos dentes carniceiros de grande parte dos animais avaliados, apresentando níveis de desgastes acentuados, causaram maloclusão.

\section{Fratura dentária}

As fraturas dentárias foram observadas em 38 espécimes de 89 estudados, correspondendo a $42,69 \%$ do total de animais avaliados (Fig.8). Foram observadas fraturas complicadas e não-complicadas, ou seja, com e sem exposição de câmara pulpar nos animais (Fig.9). Em 15 casos foi encontrada exposição de câmara pulpar, onde três sincrânios eram provenientes de cativeiro, sete de vida livre e cinco de procedência não determinada. Foram observadas três fraturas dentárias em espécimes jovens, com dentição mista. Foi observada diferença estatisticamente significativa quanto à prevalência de fratura dentária entre os animais de vida livre $(62,96 \%)$ e os de cativeiro $(33,33 \%)$ $(\chi 2=1,064, p=0,3023)$ e quanto ao número de fraturas encontradas entre os dois grupos ( $\mathrm{U}=369,0, \mathrm{p}=0,6376)$.

Os dentes mais acometidos foram os pré-molares, grupo dentário que em conjunto atingiu $45,7 \%$ dos dentes acometidos com fraturas, sendo que destes, os primeiros pré-molares foram os mais afetados (18,52\%). Após isso, se seguiram os caninos $(28,4 \%)$, que foram os mais prevalentes, quando considerados individualmente. Os incisivos apresentaram índice de $19,75 \%$, seguidos pelos molares $(6,1 \%)$. Dentina terciária também foi formada para proteção dos dentes afetados. Fraturas de esmalte também foram observadas em 41 espécimes, sendo mais prevalente em caninos, seguido por pré-molares, incisivo e molar. Os animais de cativeiro apresentaram alta incidência dessa afecção (81,5\%), enquanto que os de vida livre se restringiram a $48 \%$.

\section{Escurecimento dentário}

Foram documentados 23 casos de escurecimento dentário, todos relacionados com trauma dentário e envolvimento de câmara pulpar, muitas vezes exposta. Dentre os indivíduos observados, um era procedente de cativeiro,

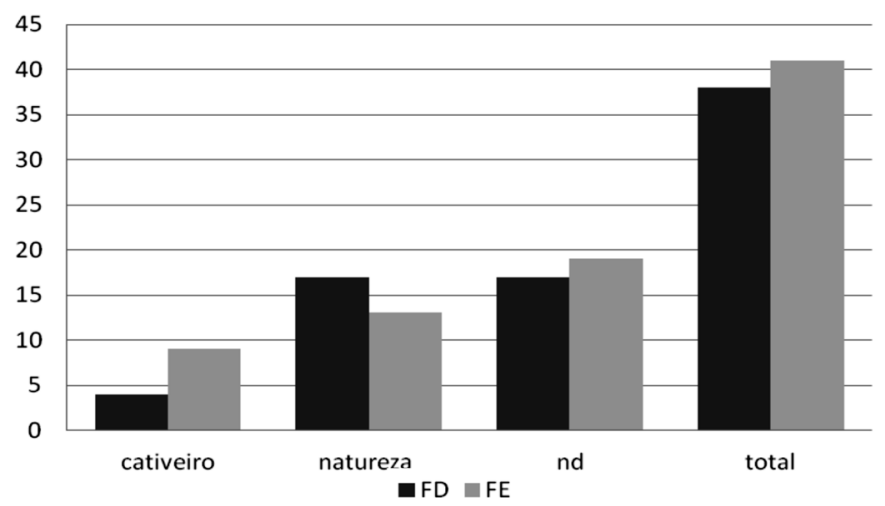

Fig.8. Mão-pelada (Procyon cancrivorus), sincrânios: Incidência de fratura dentária (FD) e fratura de esmalte (FE) por ambiente.
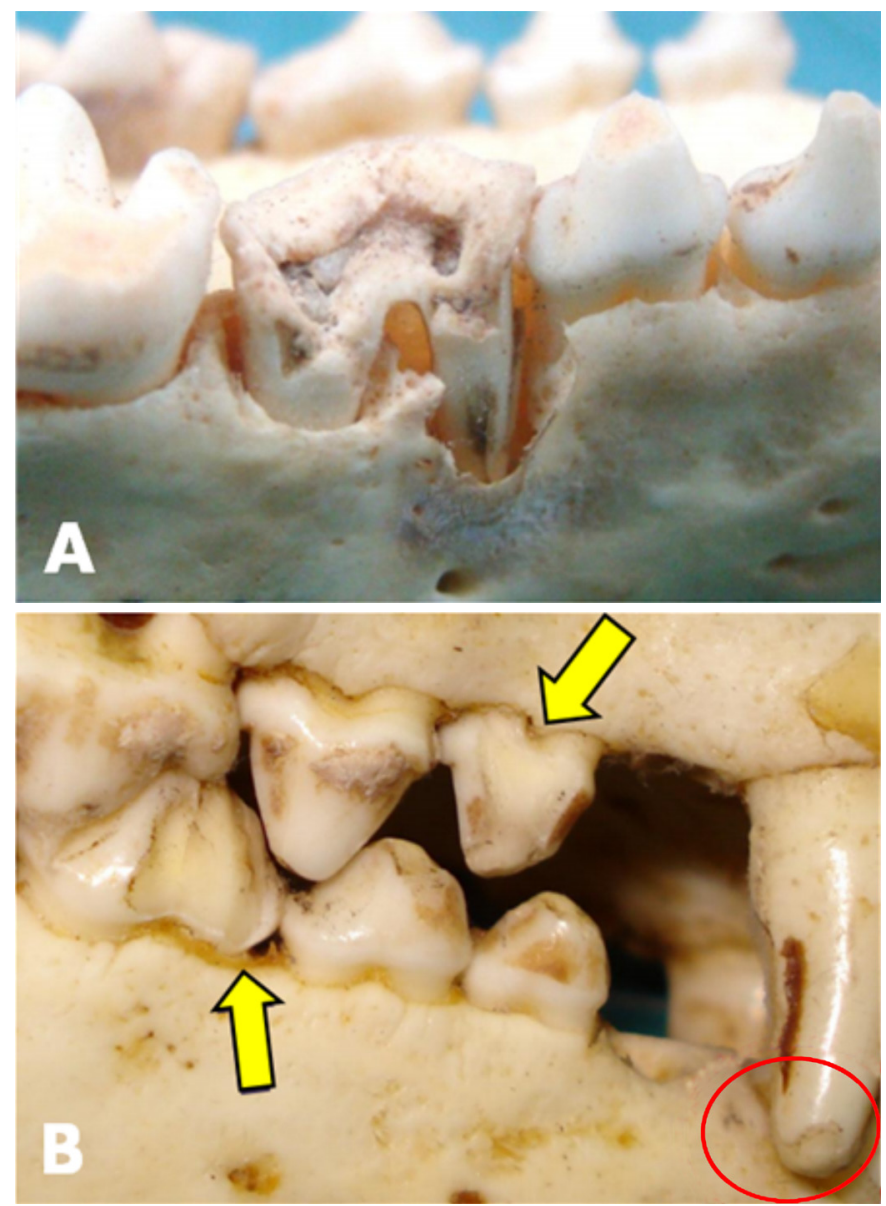

Fig.9. Mão-pelada (Procyon cancrivorus), sincrânios: (A) Fratura complicada (com exposição de câmara pulpar), envolvendo coroa e raiz na face vestibular de 408. (B) Fratura dentária não complicada em face vestibular, envolvendo a coroa em 106 e 408 (setas). Fratura de esmalte em 104 (evidenciado por elipse), 406 e 407.

$1,12 \%$ do total dos animais cativos, e quatro de natureza, $4,49 \%$ dos animais de vida livre. $20,22 \%$ (18) eram de animais de origem não determinada.

\section{Pigmentação de esmalte}

Dos indivíduos avaliados, 63 (70,78\%) apresentaram algum nível de pigmentação dental externa, isto é, circunscrita ao esmalte. Desses, apenas um indivíduo de cativeiro apresentou esta alteração $(1,12 \%$ do total avaliado e 8,33\% do total de animais de cativeiro), enquanto que 23 sincrânios procedentes de natureza $(25,84 \%$ do número total de sincrânios e 85,19\% entre os de vida livre) foram contabilizados. Foram encontrados 39 sincrânios com pigmentação de esmalte $(43,82 \%$ do total e $78 \%$ dos não determinados) entre os indivíduos sem origem catalogada. Em um único caso de animal jovem em troca de dentição, oriundo de natureza, observou-se intensa pigmentação de esmalte em caninos mandibulares.

\section{DISCUSSÃO}

A utilização de sincrânios para avaliação das afecções orais foi extremamente valiosa, pois este é um material resis- 
tente e duradouro, passível de ser conservado por período indeterminado, ficando acessível à pesquisa científica, nas suas mais diversas formas. De fato, conforme ressalta Rossi Junior (2007), há possibilidade de a pesquisa ser ampliada futuramente, da mesma maneira que ocorreu com Colyer (1936), que posteriormente foi complementado por Tucker (1954). Outro aspecto referente ao estudo de sincrânios coletados e depositados nos acervos de instituições de ensino e pesquisa é o fato de se permitir contato com o material preservado, que muitas vezes é de difícil acesso no seu ambiente natural. Os ossos e dentes também são excelentes fontes de avaliação das condições adversas que os animais enfrentaram em ambiente natural, que provavelmente não tenham sido determinantes das suas mortes, mas que não seriam possíveis de se observar enquanto vivos (Rossi Junior 2007). As observações realizadas no presente estudo concordaram com diversos autores, que relataram marcante diferença na anatomia dentária de Procyon cancrivorus em comparação com outros membros da ordem carnívora, revelando suas diferentes habilidades mastigatórias, que inclui número e forma dos elementos dentários (Zeveloff 2002, Teixeira \& Ambrosio 2006, Rossi Junior 2007). Especial contraste se observou nos dentes carniceiros, que além de apresentarem forma e função bastante distintas das de outros carnívoros, apresentaram relevantes diferenças nos tipos, formas e graduação das afecções ou transformações ocorridas durante a vida, pelo uso do aparato mastigatório, quando comparados com outras espécies estudadas, como os cães domésticos (Gioso \& Carvalho 2005), cães e gatos (Kowaleski 2005); felídeos selvagens (Rossi Junior 2007), e lobos-guará (Lopes 2008). Foi observada alta incidência de variadas afecções dentárias, em condições semelhantes de ocorrência, como o traumatismo, que incluiu desgaste $(95,5 \%)$, fraturas de esmalte $(46 \%)$ e dentárias $(42,7 \%)$, anomalias dentárias (61\%) e doença periodontal $(85,4 \%)$, sendo que um mesmo animal costumava apresentar intensidade e prevalência parecidas de mais de uma lesão, concomitantemente. Tais achados concordam com estudos de Hungeford et al. (1999) em raccoons, onde indivíduos que apresentavam escore elevado para uma afecção oral, tendiam a ter valores elevados para todos os outros índices. Referente aos traumas, este estudo concorda com Johnson (2008), que descreveu a doença dentária e fratura de caninos como as desordens orais mais comuns em Procyon lotor, embora não tenha feito relato em $P$. cancrivorus. Os mesmos achados são também relatados em canídeos selvagens, onde as lesões traumáticas prevaleceram (Wiggs \& Lobprise 1997) em lobos-guarás (Lopes 2008) e em felídeos selvagens de cativeiro que apresentaram alta prevalência de fratura e desgaste dentário (Rossi Junior 2007).

Embora a literatura moderna atribua ao ambiente de cativeiro maior ocorrência de fraturas dentárias, geralmente relacionadas com problemas comportamentais e de agressividade (Wiggs \& Lobprise 1997, Wenker et al. 1999, Pachaly \& Gioso 2001, Wiggs \& Bloom 2003), o presente estudo concorda com Verstraete et al. (1996), Hungeford et al. (1999), e Lopes (2008); demonstrando que esta afecção dentária também ocorre com frequência em vida livre, e relacionam a provável causa com características e hábitos alimentares característicos dessas espécies em natureza. No presente trabalho a ocorrência de fraturas complicadas e níveis de desgaste acentuado foram mais prevalentes do que os encontrados por Lopes (2008) em Chrysocyon brachyurus e por Rossi Junior (2007) em Panthera onca e Puma concolor. Supõe-se que esse fato se dá, provavelmente, pela dieta alimentar do P. cancrivorus, que é particularmente composta de conchas de mariscos e cascos de crustáceos (Zeveloff 2002, Teixeira \& Ambrosio 2006). Segundo Phillips \& Olson (2005), raccoons podem viver até 20 anos em cativeiro, enquanto que em vida livre, os registros de idade estimada não passam de cinco anos. Este dado se torna importante, quando avaliamos a diferença entre o número e a gravidade de fraturas dentárias, em animais provenientes de cativeiro $(33,33 \%)$ e de vida livre $(62,97 \%)$. Tal fato pode ser um fator incisivo na relação entre saúde oral e longevidade, levando em consideração que, apesar de ser um animal oportunista, que pode variar sua fonte alimentar e se adequar a situações adversas (Hungerford et al. 1999), na natureza esta adaptação torna-se mais difícil, pela menor oferta de novos alimentos, quando comparada à vida em cativeiro. 0 nível de desgaste, no entanto, que foi encontrado em alta prevalência nos seus mais diversos graus, de forma similar, tanto em animais de cativeiro como de vida livre, pode se relacionar exatamente com essa longevidade, ocorrente em animais de cativeiro, que por viverem mais, teriam utilização de seus dentes por mais tempo, sofrendo o desgaste proeminente, que faz parte da biologia de $P$. cancrivorus. No que se refere à fratura de esmalte, no entanto, a prevalência desta ocorrência não acompanhou a de fratura dentária, que foi mais prevalente em animais provenientes de natureza, já que animais de cativeiro apresentaram maior incidência de fratura de esmalte $(81,5 \%)$, enquanto que os de vida livre se restringiram a $48 \%$. Esse fato pode ser devido à maior ocorrência de lesões de oclusão e apinhamento dentário, observados no presente estudo, que foram significativamente mais frequentes em animais mantidos em cativeiro.

Com relação aos dentes mais afetados pelo desgaste dentário, achados deste estudo concordaram com Wenker et al. (1999) em ursos-pardos e Lopes (2008) com lobos-guará, que relataram os incisivos como os mais acometidos. No entanto, no caso dos mãos-peladas, o desgaste dos pré-molares e molares, especialmente os quartos pré-molares e primeiro molares, não apresentaram diferença significativa da ocorrida em incisivos. Além do mais, os dentes mais acometidos com desgaste nível 4, foram exatamente os carniceiros, o que confirma a característica da espécie de mastigar bem os alimentos, que em grande parte das vezes é duríssimo. Rossi Junior (2002) correlacionou desgaste prematuro de esmalte ou dentina com maloclusão em felídeos selvagens. Da mesma forma, foi observada correlação entre o nível de desgaste e problemas de maloclusão, em animais pertencentes ao acervo do MPEG, coletados entre o período de 1908 e 1944, todos pertencentes a Jardim Zoológico. Os dentes mais afetados por desgaste foram os incisivos e os molares.

Mesmo sendo relatada a maloclusão em diversos carnívoros selvagens, como uma afecção mais propensa de 
ocorrer em animais de cativeiro do que em animais de vida livre (Wiggs \& Lobprise 1997, Wiggs \& Bloom 2003), os achados deste estudo ressaltam que há possibilidade de ter havido influência da localização e procedência da maioria dos animais de cativeiro avaliados, que possivelmente pertenciam ao mesmo Jardim Zoológico, o que não foi registrado no momento do tombamento do material avaliado. Circunstâncias ambientais nutricionais, textura da dieta, estresse, trauma e doença periodontal (Wiggs \& Lobprise 1997, Wiggs \& Bloom 2003) podem ter sido decisivas na implantação e manutenção dessas lesões. Outra hipótese a ser verificada é a possibilidade de transmissão genética dessas características, no caso de se tratar de um mesmo ramo familiar. Nisso concordam Fitch \& Fagan (1982), que em estudo realizado com guepardos, levantaram a hipótese de que quase todos os casos de erosão palatina focal (FPE) descritos na espécie podem ter sido herdados, sugerindo fatores genéticos, uma vez que foram encontrados em animais importados de uma mesma área do sudoeste da África em 1970, ou dos seus descendentes. Com relação a traumas, Rossi Junior (2002, 2007) e Lopes (2008), inferem que a localização anatômica e o tamanho dos dentes podem predispor a diferentes forças durante sua utilização, levando a fraturas. 0 dente canino foi citado como o mais afetado, pelos dois autores, o que se equiparou a este estudo, onde os caninos foram os dentes mais afetados $(28,4 \%)$, quando considerados individualmente. No entanto, os pré-molares, grupo dentário que em conjunto atingiu 45,7\% dos dentes acometidos com fraturas, foram de longe os mais afetados, sendo que destes, os primeiros pré-molares foram os que mais sofreram $(18,52 \%)$.

Ainda foram documentadas perdas dentárias ante-morte, num percentual de 42,7\% dos sincrânios avaliados, número bastante expressivo e que corrobora com a singularidade da biologia do animal estudado. Foram observados também 23 casos de escurecimento dental (25,84\%), todos relacionados com trauma dentário e envolvimento de câmara pulpar. Rossi Junior (2002) relatou baixa incidência dessa afecção em felídeos estudados apesar da alta frequência de traumatismo relacionando o escurecimento interno dos dentes com o rompimento de vasos pulpares e penetração de substância nos túbulos dentinários.

Nas coleções de todos os acervos estudadas no presente trabalho, as anomalias dentárias foram altamente prevalentes, correspondendo a 68,54\% do total de animais. Tais alterações foram discrepantes das encontradas por Rossi Jr (2007) em pumas e onças-pintadas, e Lopes (2008), que observou que apenas $26,5 \%$ do total de lobos-guarás apresentavam anomalias dentárias. Dentro das lesões incluídas no grupo de anomalias dentárias, os achados desse estudo também não foram condizentes com Lopes (2008), que relatou a presença de raiz acessória e o apinhamento dentário como as afecções mais prevalentes em lobos-guarás, enquanto que em mãos-peladas, os casos de giroversão, com $51,68 \%$, obtiveram os maiores percentuais observados. Não houve diferença quanto à incidência de giroversão dentária encontrada por bioma. A maior incidência em $P$. cancrivorus pode ter sua causa relacionada com sua conformação craniana, que é mesocefálica, enquanto que os Chrysocyon brachyurus são dolicocéfalos (Lopes 2008). Porém, mais estudos são necessários para configurar esta hipótese. Apinhamento dentário também foi um achado frequente, com 30\% dos sincrânios acometidos, sendo que foi mais prevalente em animais procedentes de cativeiro, $83,33 \%$, contra $22,22 \%$ dos oriundos de vida livre. Como essa alteração foi também associada a outras afecções de conformação, como maloclusão, e desgaste irregular, e pela procedência da maioria das amostras de cativeiro ser de um único acervo, faz-se necessária uma investigação mais criteriosa das prováveis causas dessa alteração, especificamente.

Foram encontrados 76 indivíduos com sinais osteológicos de doença periodontal, 85,39\% do total de sincrânios estudados, sendo que a maior incidência foi em animais procedentes de cativeiro. Estes achados foram compatíveis com Hungeford et al. (1999), em P. lotor, que encontraram maior prevalência e maior gravidade dessas lesões em animais de um parque, com grande proximidade humana, em contrapartida com o grupo de natureza. Esses dados também são compatíveis com diversos relatos na literatura (Wiggs \& Lobprise 1997, Wenker et al. 1999, Miles \& Grigson 2003, Wiggs \& Bloom 2003, Rossi Junior 2007; Lopes, 2008). Da mesma forma que estes autores, o presente estudo confere às alterações da dieta e hábitos alimentares, grande parte da responsabilidade por esse conjunto de lesões. Assim como a presença de cálculo, que também foi um achado frequente $(58,43 \%)$, e que divergiu bastante, conforme o ambiente de procedência. Verificou-se que 83,33\% do total de animais de cativeiro estudados apresentaram esta afecção, enquanto que apenas metade do grupo dos espécimes procedentes de natureza. A presença dessa lesão em mãos-peladas difere notoriamente da encontrada por Rossi Junior (2007) em P. onca, onde não foi observada essa lesão. Quanto ao grau, as amostras derivadas de cativeiro apresentaram o dobro de ocorrência de coeficientes mais elevados, quando comparados com os de vida livre. Neste caso, concorda-se relato em literatura de que a etiologia da maioria das doenças orais está relacionada com características físicas de sua dieta e às mudanças químicas a que estas dietas induzem (Fitch \& Fagan 1982). Erosão de esmalte foi encontrada em $24,72 \%$ dos mãos-peladas examinados e foi mais prevalente nos dentes incisivos e caninos, o que diferiu de Rossi Junior (2002), que relatou baixa incidência dessa lesão, afetando principalmente caninos e pré-molares. Foi encontrada uma lesão sugestiva de cárie, que não pode ser confirmada microscopicamente, mesmo obstáculo encontrado por Rossi Junior (2002), que conferiu a tal lesão a denominação de destruição amelo-dentinária. Lopes (2008) descreveu que 11,4\% dos animais avaliados apresentaram dentes acometidos por lesões sugestivas de cárie, sem variação significativa de ambiente, com o que também concordou o presente trabalho. Este autor também não realizou análise microbiológica nem histopatológica das lesões para confirmação do diagnóstico de cárie. Hungeford et al. (1999), no entanto, referiram que em raccoons acometidos com cáries, a maior prevalência se deu na região de um parque, onde o contato com seres humanos e seus alimentos foi intenso. Estes autores acreditam 
as diversas afecções orais - dentre elas gengivite e doença periodontal - foram causadas não só por traumas físicos, ao usarem os dentes para abrir vasilhames e latas de lixo, mas também por deficiências nutricionais específicas relacionadas a uma dieta rica em carboidratos, somando-se à presença de elevado nível de decomposição bacteriana. Talvez, tal achado não tenha sido tão frequente nos sincrânios provenientes de cativeiro observados no presente estudo, pelo fato dos animais serem oriundos de zoológicos, que oferecem melhor qualidade dietética do que os restos alimentares humanos roubados de latas de lixo no parque em questão.

Reabsorção óssea alveolar foi encontrada em metade dos sincrânios avaliados, resultado similar ao encontrado por Lopes (2008) em lobos-guarás. No entanto, em estudo realizado com canídeos selvagens, Miles \& Grigson (2003) afirmaram que a reabsorção óssea alveolar é incomum nestes animais, sendo observada, ainda, prevalência mais elevada em algumas espécies do que em outras. A mesma constatação foi feita com relação à baixa incidência em sincrânios de $P$. onca e $P$. concolor, segundo documentado por Rossi Junior (2007). Maior prevalência de deiscência se deu nos segundos molares superiores, mas, também foi observada em outros dentes, como nos seus vizinhos, os primeiros molares maxilares. 0 dobro da ocorrência foi em animais de cativeiro. Lopes (2008), no entanto, não encontrou diferença no número de animais acometidos nos dois ambientes. Esses achados, uma vez mais, revelam importante diferença na biologia de $P$. cancrivorus, quando comparado com outros carnívoros, especialmente no que tange aos hábitos alimentares, fazendo-nos reavaliar alguns dos critérios de classificação de carnívoros. De fato, a alta incidência dessa afecção nos espécimes de lobos-guará avaliados por Lopes (2008) sugere ao autor a possibilidade deste defeito ósseo ser fisiológico na espécie, já que animais sub-adultos, em fase de troca de dentição, apresentaram deiscência bilateral. Fato semelhante se deu com P. cancrivorus avaliados, que apresentaram $50 \%$ dos indivíduos em troca dentária com os mais diversos níveis de deiscência alveolar. A incidência de fenestração óssea foi similar à encontrada por Lopes (2008), em lobo-guará e mais observada em animais de cativeiro que de vida livre. Fenestração bilateral foi um achado eventual $(26,7 \%)$, na face vestibular da região molar de sincrânios apresentando dentição mista, que não entraram nas estatísticas, sendo que em todos os casos, a procedência não constava das fichas de tombamento. Tal fato sugere que essa alteração seja parte de um processo fisiológico, não influindo no estado de saúde oral do mão- pelada. Outra suposição é levantada por Miles \& Grigson (2003), que afirmaram que, apesar da etiologia ainda ser desconhecida, não há dúvida que estas lesões ocorram em outras espécies, podendo ser decorrentes não apenas de afecções locais, mas possivelmente relacionadas à atrofia esquelética ou à osteoporose. Hipótese ratificada por Lopes (2008), mas, que demanda maiores estudos.

As estatísticas de perdas dentárias não foram incluídas no grupo de anomalias dentárias, pois sua causa foi traumática ou posterior à morte do animal. No transcorrer do presente estudo não houve possibilidade de se realizar avaliação radiográfica dos sincrânios, pois não foi permitida a retirada das peças dos acervos estudados, dificultando o diagnóstico preciso de certas afecções, como ausência dentária por agenesia ou não-erupção, incidência de anomalias de raízes, além da avaliação da idade do animal, no momento da morte, pela espessura da câmara pulpar e canal radicular.

Observou-se, portanto, que Procyon cancrivorus apresenta particularidades no padrão de dentição, que o distinguem dos demais pertencentes à Ordem Carnívora. As afecções orais são frequentes nessa espécie, tanto em animais mantidos em cativeiro quanto de vida livre. Animais de cativeiro foram os mais acometidos com as lesões relacionadas à doença periodontal, como cálculo, reabsorção óssea alveolar, deiscência, fenestração, exposição de furca, apinhamento dentário e os níveis mais acentuados de desgaste dentário. Os animais de vida livre apresentaram mais altos índices de fraturas, perdas dentárias ante-morte e escurecimento dentário. Os hábitos alimentares dos animais de natureza são responsáveis por importantes enfermidades na espécie estudada. A principal anomalia dentária observada nos mãos-peladas consistiu na giroversão dentária, acometendo principalmente os segundos e terceiros pré-molares mandibulares, bilateralmente. Fenestração e deiscência foram achados frequentes na região de quarto pré-molar e molares superiores, independente do bioma. A pigmentação dentária foi mais prevalente em animais de vida livre.

Agradecimentos,- Aos curadores e técnicos do Museu Paraense Emílio Goeldi, Museu Nacional do Rio de Janeiro, Museu de Mastozoologia da Universidade de São Paulo, e à Universidade Vila Velha/ES, pela confiança em permitir o acesso ao seu acervo. À Fundação de Amparo à Pesquisa do Estado do Espírito Santo (FAPES), pelo auxílio à pesquisa e bolsa.

\section{REFERÊNCIAS}

Arispe R., Venegas C. \& Damián R. 2008. Abundancia y patrones de actividad del mapache (Procyon cancrivorus) en un bosque chiquitano de Bolivia. Mastozoología Neotropical 15(2):323-333.

Cheida C.C., Nakaro E.O., Quadros J., Costa R.F. \& Rocha F.M. 2006. Ordem Carnivora, p.231-275. In: Reis N.S., Perachi A.L., Pedro W.A. \& Lima I.P. (Eds), Mamíferos do Brasil. Nélio R. dos Reis, Londrina. 437p.

Cooper J.E. \& Cooper M.E. 2008. Skeletal pathology of primates and other wildlife. Vet. Rec. 162(2):63-64.

Colyer F. 1935. Variations and Diseases of the Teeth of Animals. Cambridge University Press, Cambridge, p.660-690.

Einsenberg J.F. \& Redford K.H. 1999. Mammals of the Neotropics. Vol.3. The Central Neotropics: Ecuador, Peru, Bolivia, Brazil. University of Chicago Press, Chicago. 609p. (Apud Cheida et al. 2006)

Elbroch M. 2006. Animal skulls: A guide to North American species. Stackpole Books, Mechanicsburg. 726p.

Fecchio R.S., Gomes M.S., Rossi Junior J.L. \& Gioso M.A. 2008. Oral diseases in captive capuchin monkeys. Exotic DVM: a practical resource for clinicians 10(2):15-20.

Fecchio R.S., Rossi Junior J.L., Ferro D.G. \& Gioso M.A. 2009. Medicina preventiva aplicada à odontologia veterinária em animais selvagens. Nosso Clínico 12:44-52.

Fitch H.M. \& Fagan D.A. 1982. Focal palatine erosion associated with dental malocclusion in captive cheetahs. Zoo Biology 1:295-310.

Forrier R.C., Miller T. \& Swigert J. 1969. Root canal therapy on two polar bears: case report. Proc. Am. Assoc. 155:115-119.

Gioso M.A. \& Carvalho V.G.G. 2005. Oral anatomy of the dog and cat in 
veterinary dentistry practice. Vet. Clin. North Am., Small Anim. Pract. 35(4):763-780.

Gioso M.A., Fecchio R.S., Rossi Junior J.L., Bizaroli K.J. \& Silva M.A.B. 2008. Necropulpectomia e pulpectomia total em dentes caninos de tigre siberiano (Panthera tigris altaica). Nosso Clínico 11:28-35.

Hungerford L.L., Mitchell M.A., Nixon C.M., Esker T.E., Sullivan J.B., Koerkenmeier R. \& Marretta S.M. 1999. Periodontal and dental lesions in raccoons from a farming and a recreational area in Illinois. J. Wildl. Dis. 35(4):728-734.

Johnson D. 2008. Racoon (Procyon lotor). Exotic DVM: A practical resource for clinicians 8(6):24.

Kowalesky J. 2005. Anatomia dental de cães (Canis familiaris) e gatos ( $\mathrm{Fe}$ lis catus): considerações cirúrgicas. Dissertação de Mestrado em Cirurgia, Faculdade de Medicina Veterinária e Zootecnia, Universidade de São Paulo, São Paulo, SP. 182p.

Lascala N.T. \& Moussalli N.H. 1980. Periodontia Clínica: especialidades afins. Artes Médicas, São Paulo. 335p.

Lopes F.M. 2008. Avaliação do sistema estomatognático e de sincrânios de lobo-guará (Chrysocyon brachyurus) em vida livre e cativeiro. Dissertação de Mestrado em Cirurgia, Faculdade de Medicina Veterinária e Zootecnia, Universidade de São Paulo, São Paulo, SP. 151p.

Miles A.E.W. \& Grigson C. 2003. Colyer's Variations and Diseases of the Teeth of Animals. Cambridge University Press, Cambridge. 672p.

Pachaly J.R. \& Gioso M.A. 2001. The oral cavity, p.1-15. In: Fowler M.E. \& Cubas Z.S. (Eds), Biology, Medicine and Surgery of South American Wild Animals. Iowa State University Press, Ames.

Phillips N. \& Olson L. 2005. Procyon cancrivorus (on-line), Animal Diversity. Disponível em <animaldiversity.ummz.umich.edu/site/accounts/ information/Procyon_cancrivorus.html> Acessado em 3 ago. 2008.

Rossi Junior J.L. 2002. Estudo comparativo entre os achados clínicos de lesões orais em onça-pintada (Panthera onca) e suçuarana (Puma conco- lor) mantidas em cativeiro no estado de São Paulo e indivíduos de vida livre no Pantanal Sul Mato-Grossense. Dissertação de Mestrado em Medicina Veterinária, Faculdade de Medicina Veterinária e Zootecnia, USP, São Paulo, SP. 97p.

Rossi Junior J.L. 2007. Avaliação do sistema estomatognático e de sincrânios de onça-pintada (Panthera onca) e puma (Puma concolor) capturados ou coletados em natureza. Tese de Doutorado em Medicina Veterinária, Faculdade de Medicina Veterinária e Zootecnia, USP, São Paulo, SP. 132p.

Teixeira R.H.F. \& Ambrosio S.R. 2006. Carnivora - Procyonidae, p.571-583. In: Cubas Z.S., Silva J.C.R. \& Catão-Dias J.L. (Eds), Tratado de Animais Selvagens: medicina veterinária. Roca, São Paulo.

Tucker R. 1954. Studies in functional and analytical cranioloy. Aust. J. Zool. 2:427-430.

Verstraete F.J.M., Van Aarde R.J., Nieuwoudt B.A., Mauer E. \& Kass P.H. 1996. The dental pathology of feral cats on Marion Island, Part I: congenital, developmental and traumatic abnormalities. J. Comp. Pathol. 115(3):265-282.

Verstraete F.J.M. 2007. Recognizing the normal oral anatomy in dogs and cats. Proc. Companion Animals Programme, Voorjaarsdagen, Amsterdam, p.41-43. (Abstract)

Wenker C.J., Stick H., Muller M. \& Lussi A. 1999. A retrospective study of dental conditions of captive brown bears (Ursus arctos spp.) compared with free-ranging Alaskan grizzlies (Ursus arctos horribilis). J. Zoo Wildl. Med. 30(2):208-221.

Wiggs R.B. \& Bloom B.C. 2003. Exotic placental carnivore dentistry. Vet. Clin. North Am., Exotic Anim. Pract. 6(3):571-599.

Wiggs R.B. \& Lobprise H.B. 1997. Veterinary Dentistry: principles and practice. Lippincott-Raven, Philadelphia. 748p.

Zeveloff S.L. 2002. Raccoons: A natural history. Smithsonian Institution, Washington, DC. 200p. 